\title{
Investigation of the Effects of Horticultural Activity Program for Mothers to Improve Relationship with Child
}

\author{
Yeon Seon $\mathrm{Kim}^{1}$ and Sin Ae Park ${ }^{1,2 *}$ \\ ${ }^{1}$ Department of Horticultural Therapy, Graduate School of Agricultural and Animal Science, Konkuk University, Seoul 05029, South Korea \\ ${ }^{2}$ Department of Environmental Health Science, Konkuk University, Seoul 05029, South Korea
}

\begin{abstract}
This study was conducted to find the effectiveness of a horticultural activity program for mothers to improve the relationship between mother and child. The target participants were comprised of 60 mothers who have a child aged between 4 to 7 years, and they were divided into the experimental group $(n=30)$ and the control group $(n=30)$. Those of the experimental group attended 6 sessions of the horticultural activity program in total (one session per week, 90 minutes on average), and those of the control group did not participate in the program. A survey on parenting stress, self-esteem, parenting efficacy and emotional empathy was conducted before and after the program. Its results indicated that the participants of the experimental group showed statistically significant improvements in the parenting stress level (associated with the characters of children, the relationship with them, and learning expectation). Their self-esteem also showed statistically significant improvements from perspectives of self-abasement, relationships with others, leadership and popularity, and assertiveness and anxiety. Their parenting efficacy including efficacy as a parent; anxiety and frustration as a parent; and interest and attention to parental roles showed statistically significant improvements, but there was no statistically significant difference in emotional empathy including emotional sympathy and empathic concern. In addition, the results of the satisfaction survey conducted among the mothers of the experimental group after the program indicated that their satisfaction of the overall program, the time required for a session, and the frequency of the program was high. In this study, it was found that positive changes could be realized through the horticultural activity program for the improvement of the relationship between mother and child by modifying relevant factors. It is expected that the participants of the study may experience more positive improvements if they can join horticultural activities with their child later, and it is necessary to develop programs that can engage parents in other environments based on the results of this study.
\end{abstract}

Key words: horticultural therapy, parent education, parent-child relationship, socio horticulture, urban horticulture

\section{I . Introduction}

A child's first relationship starts with the mother, and the positive relationship with the mother plays a important role in the growth and development of a child (Cho et al., 2013). A dysfunctional relationship between mother and child can lead to psychological anxiety in a child, causing maladjustment, aggressive behaviors, problems in the relationship with peers, contracted behaviors, and dependence (Jeong and Lee, 2010a; Miller and Olsen, 2000; Park, 2004).

Under the recognition of the importance of the positive relationship between child and parents, there have been various education programs conducted for parents to improve their

Received on December 5, 2016. Revised on December 13, 2016.

Accepted on December 20, 2016.

*Comesponding author: sapark42@konkuk.ac.kr relationship with children, parenting attitudes, and communication skills. For instance, it was found that education programs for parents based on the transactional analysis theory had a positive effect on parenting attitudes and communication skills (Kong, 2010). Such programs have been mostly introduced from abroad, and used directly without modification or supplementation to suit the circumstances of Korea. As they focused only on parental methods not on changes in the inner mind of parents, several side effects have been reported. For this reason, there has been a growing demand for the development of parental education programs (Ryu, 1996; Yang, 1987; Yeon, 1994).

Meanwhile, horticultural therapy is one of the alternative therapies to seek the recovery and rehabilitation of human body and mind through plants and horticultural activities (Son et al., 2006). Such activities can bring about changes in the 
mind of parents, and mothers can be reminded of the importance of child rearing through the entire cycle of a plant's life (Choi and Seo, 2007). There have been several studies conducted on horticultural programs for the improvement of the relationship between parents and children. According to Hwang et al. (2007), it was found that mothers of elementary school students experienced significant improvements in their depression and stress through 15 sessions of horticultural activities including planting, and arranging real and artificial flowers, which led to positive effects (Hwang et al., 2007). In another study, it was also found that 16 sessions of indoor horticultural activities comprised of planting, and making crafts had positive effects on the improvement of the interpersonal relations and sociality of mothers (Hong, 2009). It was also found that mothers in single-parent families experienced the recovery of their psychological and emotional states, and improvements in sociality and interpersonal relations through 9 sessions of horticultural activities (Cha, 2009).

Thus, this study was conducted with the aim of finding the effectiveness of a horticultural activity program for mothers in improving their relationship with children.

\section{Materials and Method}

\section{Participants}

This study targeted mothers who were rearing a child aged between 4 to 7. To recruit research participants, about 100 copies of the research brochure containing information on this study were distributed to preschools and daycare centers in Gangiin-gu, Seoul and Jangan-gu, Suwon from July to October, 2014. Research participants were selected among mothers of a child aged 4-7 years who wanted to participate in this study and signed an consent form. Out of the 60 final participants in total, 30 people were randomly selected as an experimental group who participated in a horticultural activity program, and the rest 30 people were compared as an control group. Prior to the first session of the horticultural activity program, the participants were informed of detailed information on this study (content, schedule, etc.) through an orientation meeting. All participants both in the experimental and control groups filled out a survey on their demographic information (age, educational level, occupation, monthly income and the number of children). This study was reviewed and approved by the Institutional Review Board of the Konkuk University (7001355-201407HR-026).

\section{Research design}

The horticultural activity program was carried out from August to November, 2014, and the experimental group was divided into 3 subgroups: 8 participants in K university located in Seoul; 10 participants in $\mathrm{F}$ center located in Gyeonggi Province; and 12 participants in $\mathrm{H}$ preschool located in Gyeonggi Province. In total, 6 sessions were conducted for each subgroup — once a week and 90 minutes, and 2 to 3 participants joined the program as a small group. The program was conducted indoor in a space sized around 15 pyeong $\left(50 \mathrm{~m}^{2}\right)$, and its activities were led by one main therapist [a holder of the first grade certificate of horticultural therapist issued by the Korean Horticultural Therapy and Well-Being Association (KHTA)]. The overall attendance rate of the participants was around $98 \%$.

3. Horticultural activity program for mothers to improve their relationship with children

The horticultural activity program developed for this study

Table 1. A 6-Session of horticultural activity program for improving relationship between mother and child.

\begin{tabular}{lcl}
\hline Session & Subject & \multicolumn{1}{c}{ Plant materials used } \\
\hline 1 & Flower arrangement & Gentiana scabra bunge var. buergerii Max, Eucalyptus globulus, Setaria italica, Crocosmia pottsii (Bak.) \\
2 & Planting & Podocarp nagi Masaki japonica 'Nakai', Lemmaphyllum microphyllum 'Presl' \\
3 & Hydroponics & Chamaedorea elegans 'Parlour Palm', Spathiphyllum spp. 'Spathe flower', Hedera helix 'English Ivy' \\
4 & Planting & Codiaeum variegatum, Fittonia 'Pink Star' \\
5 & Planting & Chamaecyparis pisifera (Sawara Cypress), Fittonia 'White Star' \\
6 & Planting & Sedeveria letizia, Anacampseros rufescens, Haworthia obtusa \\
\hline
\end{tabular}


was comprised of 6 sessions of indoor planting activities (Table 1). According to the meta analysis study about the effectiveness of parental education programs (Cho et al., 2013), programs with 6-10 sessions accounted for the majority (81\%) of the parental education programs conducted from 2002 to 2011, and thus it was decided to conduct 6-sessions in this study.

Those that were used for the horticultural activity program in this study include Masakia japonica (Nakai), Podocarpus nagi ((Thunb.) Zoll et Moritzi), Lemmaphyllum microphyllum (Presl), Spathiphyllum spp. (Spathe flower), Chamaedorea elegans (Parlour Palm), Hedera helix (English Ivy), Codiaeum variegatum (Croton), Fittonia 'Pink Star', Chamaecyparis pisifera (Sawara Cypress) and Fittonia 'White Star'.

Before developing a horticultural activity program to improve the relationship of participating mothers with child through using various plants for each session, a literature research was conducted to find out relevant factors that have a positive effect on the relationship between mother and child. For the literature research, two keywords - "parents and child"and "program"- were searched using the search engine of the Research Information Sharing Service (RISS). As a result, the numbers of dissertations and journal articles published between 2004 to 2014 were 5,070 and 1,263 respectively, and through reviewing the content, 40 research papers associated with the improvement of the relationship between mother and child were selected. Through the analysis of the selected papers, it was found that factors such as parenting stress, self-esteem, parenting efficacy and emotional empathy have an effect on the improvement of the relationship between mother and child.

Parenting stress can be defined as a type of stress that people may sense in daily lives in playing a parental role (Kim, 2007). Mother's child rearing stress can bring about a negative impact on a child's mind such as transferring stress from mother to child, and this in turn can cause anxiety, aggression, and behavioral problems in children (Choi, 2010; Han, 2011; Hwang et al., 2007). People with low self-esteem were more prone to negative attitudes such as anxiety, and fear of interpersonal relations and new environments (Choi, 2010; Kim, 2012a; Lee and Jeong, 2006; Park and Chung, 2002). The higher mothers' self-esteem is, the more positive attitudes mothers can have toward their children. Thus, those children can grow in a stable psychological state, and this in turn plays an important role in the improvement of the positive relationship between mother and child (Kim, 2012b; Suh, 2009). Dorsey et al. (1999) said that parenting efficacy is defined as the parent's belief about their capabilities to support their child's desirable development and behaviors. A mother with high parenting efficacy can actively seek solutions to problems with her child, and have capabilities to cope with every situation (Han, 2011; Hwang et al., 2007). Emotional empathy is an emotional response of empathic abilities, and an ability to empathize with others' feelings and thoughts (Kim, 2011). Parents with high emotional empathy can lead their children to a healthy life, and also have few troubles with them (Heo, 2012; Park, 2014). Each session's goal was set based on the relevant factors that were found in early studies.

Each session was divided into a series of stages: introduction, development and conclusion. In the introduction stage, the goal and overall content of the session were introduced to trigger the interest and curiosity of mothers. In the development stage, horticultural activities were arranged for each session with a therapeutic purpose to improve factors associated with the improvement of the relationship between mother and child, including "parenting stress," "self-esteem," "parenting efficacy," and "emotional empathy." In the conclusion stage, participants had time to express their thought and feelings on ways to care for plants.

In the introduction stage, they had time for discussion and presentation on the last session's activities first. Through an activity of exploring and observing plants to be planted, participants were encouraged to obtain knowledge about horticulture and to be actively engaged in the program. In the development stage, participants experienced green plants with multiple senses by shaking off soil adhering to roots for water culture. This was intended to relieve parenting stress that comes from the relationship with their child through relaxed attitudes toward plants and psychological stability. As they propped up plants with gravels around them, they were encouraged to recognize important roles of a supporter. As the roles of water and persons in charge are very crucial to aquaculture plants, this activity was particularly helpful for mothers to improve their empathic abilities. In addition, through an activity of planting plants in a pot and creating an environment for them, mothers 
could gain confidence and enhance their self-esteem. In the conclusion stage, participants discussed how they felt in the process of planting water plants and expressed their internal emotions. With this activity, they were able to recognize their parenting efficacy and child rearing ability by learning ways to care for plants. Before wrapping up the program, participants were informed of the next task in which they should care for the plant they planted for the next week, and of the content of the next session to raise their expectations.

\section{Measurements}

In this study, a survey on self-esteem, parenting stress, emotional empathy and parenting efficacy was conducted among the participants in the experimental and control groups of the program before and after the horticultural activity program to analyze the effectiveness of the program for the improvement of the relationship between mother and child.

About parenting stress, 20 questions in total were included in the survey and the translated version (Seo, 1992) of the Parenting Stress Index (PSI) of Abidin (1990) was used. The questions were divided into 3 sub-factors including stress associated with the characters of children, the relationship with them, and learning expectation, and the possible score ranged from 20 to 100 points. The 6 affirmative questions were scored backwards, which means that those who got a higher point in these questions recognized more stress from child rearing. The total reliability coefficient was 0.92 (Kim, 2010).

About self-esteem, 25 questions in total were asked, and the standardized form (Kang, 1986) of the Self-Esteem Inventory (SEI) of Coopersmith (1967) for the use in Korea was employed. The questions were divided into 4 sub-factors including selfabasement; relationships with others; leadership and popularity; and assertiveness and anxiety. A 5-point Likert scale was used to assess the questions as follows: 'strongly agree (5)', 'agree (4)', 'neutral (3)', 'disagree (2)', and 'strongly disagree (1)', and they were scored backwards. The total reliability coefficient was 0.84 (Oh, 2011).

About parenting efficacy, 16 questions in total were asked, and the translated version (Shin, 1997) of the Parenting Sense Of Competence (P.S.O.C) developed by Gibaud-Wallston and Wandersman (1978) was used. The questions were divided into 3 sub-factors including efficacy as a parent; anxiety and frustration as a parent; and interest and attention to parental roles. A 5-point Likert scale was used to assess the questions as follows: 'strongly disagree', 'disagree', 'neutral', 'agree', and 'strongly agree', and the possible score ranges from 16-80. The total reliability coefficient was 0.79 (Lee, 2010b).

For emotional empathy, 27 questions in total were asked, and the revised one for parents (Kim, 2011) of the emotional empathy questionnaires developed by Shin (1994) was used. The questions were divided into 2 sub-factors including emotional sympathy and empathic concern, and the possible score ranges from 27 to 135, which means the higher the score, the higher emotional empathy. The total reliability coefficient was 0.72 (Lee, 2012).

To assess the satisfaction of the horticultural activity program for mothers for improving the relationship between mother and child, an overall satisfaction survey was conducted among the participants of the experimental group after finishing the 6 sessions of the program. To do so, the satisfaction questionnaire developed by Park et al. (2016) for its farming class for children was referred and revised into 8 questions in total for this study including overall satisfaction of the horticultural activity program; program venue; time required for the program and the number of session per week; exclusive benefits of horticultural activities; positive effects of the horticultural activity program; and etc.

\section{Data analysis}

Technical statistics including average, standard deviation, and percentage were carried out on the demographical characteristics of the experimental and control groups and the satisfaction survey after the program using Microsoft Excel (Office 2007; Microsoft Corp., Redmond, WA, USA). To verify the homogeneity of the two groups, SPSS was used, and an independent t-test ( $p$ $<0.05)$ was conducted. Prior values were treated as covariates using SPSS to analyze the effectiveness of the horticultural activity program on the self-esteem, parenting stress and emotional empathy of the experimental and control groups before and after the program. The significance level of covariates (ANCOVA) was $p<0.05$. 


\section{Results and discussion}

\section{Demographic information}

The targeted participants of this study were 60 mothers of a child aged between 4 to 7, and divided into the experimental group (30 persons) and the control group (30 persons). As the

Table 2. Demographic characteristics of the participants in the study about improving relationship between mother and child $(\mathrm{N}=60)$.

\begin{tabular}{|c|c|c|c|}
\hline Variable & $\begin{array}{l}\text { Horticultural } \\
\text { activity (HA) } \\
\quad(n=30)\end{array}$ & $\begin{array}{l}\text { Control } \\
(n=30)\end{array}$ & Significance $^{\mathrm{z}}$ \\
\hline \multicolumn{4}{|c|}{ Mean (SD) } \\
\hline \multirow[t]{2}{*}{ Age (years) } & $36.9(3.6)$ & $37.6(3.2)$ & NS \\
\hline & \multicolumn{2}{|c|}{$N(\%)$} & \\
\hline \multicolumn{4}{|l|}{ Educational level } \\
\hline High school & $10(33.3)$ & $10(33.3)$ & \multirow{3}{*}{ NS } \\
\hline Bachelor degree & $20(66.7)$ & $17(56.7)$ & \\
\hline Master degree & $0(0.0)$ & $3(10.0)$ & \\
\hline \multicolumn{4}{|l|}{ Occupation } \\
\hline Housewife & $24(80.0)$ & $20(66.7)$ & \multirow{5}{*}{ NS } \\
\hline Professions & $2(6.7)$ & $4(13.3)$ & \\
\hline Office job & $1(3.3)$ & $3(10.0)$ & \\
\hline Business owners & $2(6.7)$ & $1(3.3)$ & \\
\hline Others & $1(3.3)$ & $2(6.7)$ & \\
\hline \multicolumn{4}{|l|}{ Religion } \\
\hline Christian & $7(23.3)$ & $7(23.3)$ & \multirow{4}{*}{ NS } \\
\hline Buddhism & $8(26.7)$ & $2(6.7)$ & \\
\hline Catholic & $1(3.3)$ & $3(10.0)$ & \\
\hline Atheist & $14(46.7)$ & $18(60.0)$ & \\
\hline \multicolumn{3}{|l|}{$\begin{array}{l}\text { Monthly income } \\
\text { (unit: } 1000 \text { won) }\end{array}$} & \multirow{6}{*}{ NS } \\
\hline Below 1,000 & $1(3.3)$ & $1(3.3)$ & \\
\hline $1,000-2,000$ & $2(6.7)$ & $1(3.3)$ & \\
\hline $2,000-3,000$ & $6(20.0)$ & $3(10.0)$ & \\
\hline $3,000-4,000$ & $6(20.0)$ & $14(46.7)$ & \\
\hline Above 4,000 & $15(50.0)$ & $11(36.7)$ & \\
\hline \multicolumn{3}{|l|}{ Number of Child } & \multirow{5}{*}{ NS } \\
\hline 1 & $8(26.7)$ & $8(26.7)$ & \\
\hline 2 & $19(63.3)$ & $19(63.3)$ & \\
\hline 3 & $2(6.7)$ & $3(10.0)$ & \\
\hline 4 & $1(3.3)$ & $0(0.0)$ & \\
\hline
\end{tabular}

${ }^{\mathrm{z}} \mathrm{NS}=$ No significance at $p<0.05$ by independent t-test. results of the comparison of the demographical information of the two groups (age, educational level, occupation, religion, monthly income and the number of children), the two groups did not show a significant difference as shown in Table 2. The average ages of the participants of the experimental and control groups were $36.9 \pm 3.6$ and $37.6 \pm 3.2$ respectively, and in terms of the number of children, $63.3 \%$ of the participants of the experimental group had two children, and $63.3 \%$ of the participants of the control group had two children.

Meanwhile, the results of the homogeneity test of the preassessment scores of the experimental group and the control group on parenting stress, self-esteem, parenting efficacy and emotional empathy did not show a statistically significant difference between the two groups (Table 3).

\section{Effectiveness of the horticultural activity program} for the improvement of the relationship between mother and child

To find the effectiveness of the horticultural activity program for mothers in improving the relationship with their child, changes before and after the program was analyzed.

The results of the comparison of sub-factors of parenting stress associated with the characters of children, the relationship with them, and learning expectation (Table 4), showed that the parenting stress level of the experimental stress after the program decreased and the difference was statistically significant. However, that of the control group did not show any statistically significant difference. It can be attributable to the horticultural

Table 3. Homogeneity test of pre-assessment score in the horticultural activity $(\mathrm{HA})$ and control groups $(\mathrm{N}=60)$.

\begin{tabular}{|c|c|c|c|}
\hline \multirow{2}{*}{ Variable } & $\mathrm{HA}(\mathrm{n}=30)$ & Control $(n=30)$ & \multirow{2}{*}{ Significance ${ }^{z}$} \\
\hline & \multicolumn{2}{|c|}{ Pre-test } & \\
\hline Parenting stress ${ }^{\mathrm{y}}$ & $46.4(9.8)^{x}$ & $45.8(11.3)$ & NS \\
\hline Emotional empathy ${ }^{\mathrm{w}}$ & $98.9(9.5)$ & $98.0(9.2)$ & NS \\
\hline Parent efficacy $^{\mathrm{v}}$ & $54.8(4.7)$ & $52.9(4.9)$ & NS \\
\hline Self esteem ${ }^{\mathrm{u}}$ & $85.6(10.4)$ & $85.7(8.5)$ & NS \\
\hline
\end{tabular}

${ }^{\mathrm{z}} \mathrm{NS}=$ No significance at $p<0.05$ by independent t-test.

${ }^{\mathrm{y}}$ Parenting stress survey (Shin, 1997).

${ }^{\mathrm{x}}$ Mean (SD).

${ }^{\mathrm{w}}$ Emotional empathy survey (Kim, 2011).

'Parent efficacy survey (Shin, 1997).

${ }^{\mathrm{u}}$ Self esteem survey (Kang, 1986). 
Table 4. Comparisons of the parenting stress between before and after the horticultural activity $(\mathrm{HA})$ and control groups $(\mathrm{N}=60)$.

\begin{tabular}{|c|c|c|c|c|c|}
\hline \multirow[t]{2}{*}{ Variable $^{\mathrm{x}}$} & \multirow[t]{2}{*}{ Group } & $\begin{array}{l}\text { Pre-test } \\
(\mathrm{n}=30)\end{array}$ & $\begin{array}{l}\text { Post-test } \\
(n=30)\end{array}$ & \multirow[t]{2}{*}{$F^{y}$} & \multirow{2}{*}{$\begin{array}{l}\text { Signifi- } \\
\text { cance }^{z}\end{array}$} \\
\hline & & \multicolumn{2}{|c|}{ Mean (SD) } & & \\
\hline \multirow{2}{*}{$\begin{array}{l}\text { Stress related } \\
\text { child's } \\
\text { character }\end{array}$} & HA & $18.3(5.3)$ & $17.5(4.7)$ & \multirow{2}{*}{44.4} & \multirow{2}{*}{$* * *$} \\
\hline & Control & $18.0(6.0)$ & $18.1(5.6)$ & & \\
\hline \multirow{2}{*}{$\begin{array}{l}\text { Stress caused } \\
\text { relation with } \\
\text { child }\end{array}$} & HA & $20.6(4.5)$ & $19.7(4.0)$ & \multirow{2}{*}{8.7} & \multirow{2}{*}{$* *$} \\
\hline & Control & $20.6(4.5)$ & $21.2(4.5)$ & & \\
\hline \multirow{2}{*}{$\begin{array}{l}\text { Stress related } \\
\text { learning } \\
\text { expectation }\end{array}$} & HA & $7.5(2.3)$ & $7.3(2.0)$ & \multirow{2}{*}{40.1} & \multirow{2}{*}{$* * *$} \\
\hline & Control & $7.1(2.5)$ & $7.1(2.5)$ & & \\
\hline
\end{tabular}

${ }^{\mathrm{x}}$ Parenting stress survey (Shin, 1997).

${ }^{\mathrm{y}} \mathrm{F}=\mathrm{Score}$ is from Analysis of Covariance with pretest scores as covariate.

${ }^{\mathrm{z}} \mathrm{NS}, *, * *, * * *$ No significance or significance. $p<0.05,0.01,0.001$, respectively.

activity program through which participating mothers formed a bond of sympathy, shared their difficulties and stress, and thus relieved their parenting stress. In addition, looking at green plants and doing activities using green plants are also effective to relieve stress by relaxing the autonomic nervous system and stabilized the emotional state of humans (Son et al., 1999).

The results of the comparison of sub-factors of self-esteem including self-abasement, relationships with others, leadership and popularity, and assertiveness and anxiety showed statistically significant improvements in three sub-factors of self-esteem in the experimental group after the horticultural activity program, but the control group did not show any statistically significant difference (Table 5). Self-esteem is a psychological factor that influences self-satisfaction through the developmental changes and adaptation of individuals (Kang, 2010). It seemed that doing activities such as planting and raising plants as well as appreciating plants through the program gave a sense of accomplishment and enhanced the confidence of mothers (Ha, 2005; Lee, 2010a). The support among mothers for their successful results of the planting activity seemed to be attributable to the enhanced confidence of individuals. These results correspond with those of an early study that applied the competence building model to horticultural activities for mothers of a disabled child to improve their self-esteem (Hong, 2009).
Table 5. Comparisons of the self-esteem between before and after the horticultural activity $(\mathrm{HA})$ and control groups $(\mathrm{N}=60)$.

\begin{tabular}{|c|c|c|c|c|c|}
\hline \multirow[t]{2}{*}{ Variable $^{\mathrm{x}}$} & \multirow[t]{2}{*}{ Group } & $\begin{array}{l}\text { Pre-test } \\
(n=30)\end{array}$ & $\begin{array}{l}\text { Post-test } \\
(\mathrm{n}=30)\end{array}$ & \multirow[t]{2}{*}{$F^{y}$} & \multirow{2}{*}{$\begin{array}{l}\text { Signifi- } \\
\text { cance }^{\mathrm{z}}\end{array}$} \\
\hline & & \multicolumn{2}{|c|}{ Mean (SD) } & & \\
\hline \multirow{2}{*}{$\begin{array}{l}\text { Self-abase- } \\
\text { ment }\end{array}$} & HA & $16.1(3.0)$ & $17.9(3.1)$ & \multirow{2}{*}{20.7} & \multirow{2}{*}{$* * *$} \\
\hline & Control & $16.8(2.3)$ & $16.5(2.2)$ & & \\
\hline \multirow{2}{*}{$\begin{array}{l}\text { Relationship } \\
\text { with others }\end{array}$} & HA & $25.8(3.2)$ & $26.3(3.4)$ & \multirow{2}{*}{3.9} & \multirow{2}{*}{ * } \\
\hline & Control & $25.5(3.4)$ & $25.2(3.4)$ & & \\
\hline \multirow{2}{*}{$\begin{array}{l}\text { Leadership } \\
\text { and popularity }\end{array}$} & HA & $20.1(3.2)$ & $20.8(2.5)$ & \multirow{2}{*}{6.8} & \multirow{2}{*}{$* *$} \\
\hline & Control & $19.7(2.7)$ & $19.4(2.6)$ & & \\
\hline \multirow{2}{*}{$\begin{array}{l}\text { Assertiveness } \\
\text { and anxiety }\end{array}$} & HA & $23.5(3.3)$ & $24.2(2.7)$ & \multirow{2}{*}{3.2} & \multirow{2}{*}{$*$} \\
\hline & Control & $23.8(3.2)$ & $23.6(3.2)$ & & \\
\hline
\end{tabular}

${ }^{\mathrm{x}}$ Self esteem survey (Kang, 1986).

${ }^{\mathrm{y}} \mathrm{F}=$ Score is from Analysis of Covariance with pretest scores as covariate.

${ }^{\mathrm{z}} \mathrm{NS},{ }^{*}, * *, * * *$ No significance or significance. $p<0.05,0.01,0.001$, respectively.

Table 6. Comparisons of the parent efficacy between before and after the horticultural activity $(\mathrm{HA})$ and control groups $(\mathrm{N}=60)$.

\begin{tabular}{|c|c|c|c|c|c|}
\hline \multirow[t]{2}{*}{ Variable $^{\mathrm{x}}$} & \multirow[t]{2}{*}{ Group } & $\begin{array}{l}\text { Pre-test } \\
(\mathrm{n}=30)\end{array}$ & $\begin{array}{l}\text { Post-test } \\
(\mathrm{n}=30)\end{array}$ & \multirow[t]{2}{*}{$F^{y}$} & \multirow{2}{*}{$\begin{array}{l}\text { Signifi- } \\
\text { cance }^{\mathrm{z}}\end{array}$} \\
\hline & & \multicolumn{2}{|c|}{ Mean (SD) } & & \\
\hline \multirow{2}{*}{$\begin{array}{l}\text { Satisfaction } \\
\text { as parents }\end{array}$} & HA & $31.4(4.1)$ & $32.7(3.5)$ & \multirow{2}{*}{10.6} & \multirow{2}{*}{$* * *$} \\
\hline & Control & $30.4(4.7)$ & $30.3(4.2)$ & & \\
\hline \multirow{2}{*}{$\begin{array}{l}\text { Anxiety and } \\
\text { frustration as } \\
\text { parents }\end{array}$} & HA & $11.5(3.9)$ & $10.3(3.2)$ & \multirow{2}{*}{13.9} & \multirow{2}{*}{$* * *$} \\
\hline & Control & $11.0(3.2)$ & $11.3(3.1)$ & & \\
\hline \multirow{2}{*}{$\begin{array}{l}\text { Concern and } \\
\text { interest about } \\
\text { parents' role }\end{array}$} & HA & $11.8(1.8)$ & $11.7(1.6)$ & \multirow{2}{*}{0.6} & \multirow{2}{*}{ NS } \\
\hline & Control & $11.5(1.9)$ & $11.2(2.0)$ & & \\
\hline
\end{tabular}

${ }^{\mathrm{x}}$ Parent efficacy survey (Sin, 1997).

${ }^{\mathrm{y}} \mathrm{F}=$ Score is from Analysis of Covariance with pretest scores as covariate.

${ }^{\mathrm{z}} \mathrm{NS},{ }^{*}, * *, * * *$ No significance or significance. $p<0.05,0.01,0.001$, respectively.

The results of the comparison of sub-factors of parenting efficacy including efficacy as a parent; anxiety and frustration as a parent; and interest and attention to parental roles showed statistically significant improvements in the experimental group after the horticultural activity program (Table 6). However, the control group did not show any statistically significant difference. Parenting efficacy is a self-recognition of a parent's own capability to rear their child and cope with the problems of their child in a desirable way (Park, 2003). In the process of 
planting plants, mothers were able to share useful information on educating their child and build a sympathy together, and they also became aware of the roles as a mother by looking at, touching and caring for plants. This seems to be effective to change the inner mind of mothers (Hwang et al., 2007).

The results of the comparison of sub-factors of emotional empathy including emotional sympathy and empathic concern did not show any statistically significant difference both in the experimental group and the control group before and after the horticultural activity program in this study (Table 7). It is believed that an effect on emotional sympathy can be enhanced, not by a short-term change, but by caring for plants and observing changes in the plants for a long time. Emotional empathy is an emotional response of sharing and indirectly experiencing others' thoughts and feelings (Kim, 2011). Unlike early eduction programs for parents, horticultural activities approach the inner mind through plants, and make people respect life and start to sympathize with others through the observation of growing plants (Bae, 2003). Elementary school students who had horticultural activities had better empathic abilities (Heo, 2012), and such improvements can raise the understanding of others, ultimately having positive effects on interpersonal relations (Han, 2011; Hwang et al., 2007; Matsuo, 2005).

\section{Satisfaction survey on the horticultural activity program}

A satisfaction survey on the horticultural activity program for improving the relationship between mother and child was

Table 7. Comparisons of the emotional empathy between before and after the horticultural activity $(\mathrm{HA})$ and control groups $(\mathrm{N}=60)$.

\begin{tabular}{|c|c|c|c|c|c|}
\hline \multirow[t]{2}{*}{ Variable $^{\mathrm{x}}$} & Group & $\begin{array}{c}\text { Pre-test } \\
(\mathrm{n}=30)\end{array}$ & $\begin{array}{l}\text { Post-test } \\
(\mathrm{n}=30)\end{array}$ & \multirow[t]{2}{*}{$F^{y}$} & \multirow{2}{*}{$\begin{array}{l}\text { Signifi- } \\
\text { cance }^{z}\end{array}$} \\
\hline & & \multicolumn{2}{|c|}{ Mean \pm SD } & & \\
\hline \multirow{2}{*}{$\begin{array}{l}\text { Emotional } \\
\text { sympathy }\end{array}$} & HA & $24.3(3.5)$ & $24.1(3.4)$ & \multirow{2}{*}{0.1} & \multirow{2}{*}{ NS } \\
\hline & Control & $24.7(3.4)$ & $24.7(3.4)$ & & \\
\hline \multirow{2}{*}{$\begin{array}{l}\text { Empathic } \\
\text { concern }\end{array}$} & HA & 74.7 (7.9) & $75.4(8.6)$ & \multirow{2}{*}{1.0} & \multirow{2}{*}{ NS } \\
\hline & Control & $73.3(8.0)$ & $73.2(8.0)$ & & \\
\hline
\end{tabular}

${ }^{\mathrm{x}}$ Emotional empathy survey (Kim, 2011).

${ }^{\mathrm{y}} \mathrm{F}=\mathrm{Score}$ is from Analysis of Covariance with pretest scores as covariate.

${ }^{\mathrm{z}} \mathrm{NS},{ }^{*},{ }^{*}, * * *$ No significance or significance. $p<0.05,0.01,0.001$, respectively. conducted among the participants of the experimental group after the program.

As shown in Fig. 1, the overall satisfaction level of the program was very high ("very satisfied", 63\%, and"satisfied", 37\%).

To the question about the average time (90 minutes) required for an individual session, $43 \%$ of the participants of the experimental group answered "very satisfied", $40 \%$, "satisfied", and 17\%, "normal" (Fig. 2).

From this result, it was found that the average time required for each session was adequate.

To the question about the satisfaction of the frequency per week, $40 \%$ of the participants answered "very satisfied", $50 \%$, "satisfied", and 10\%, "normal" (Fig. 3). These results indicated that one session per week was enough for the horticultural activity program for the improvement of the relationship between mother and child.

In addition, to the question about the benefits of the horticultural activity program developed in this study, $30 \%$ of the participants said "the composition of activities of taking care of life", 25\%, "expectation of plant's growth", 15\%, "not giving tension", $10 \%$ "pleasant therapy", $10 \%$, "occurrence of outcomes", and 7\%, "effective for rehabilitation of mind and

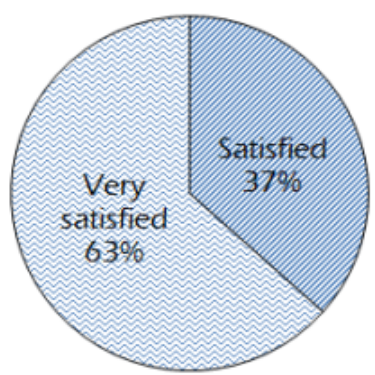

Fig. 1. Satisfaction for the horticultural activity program of the participants $(\mathrm{N}=30)$.

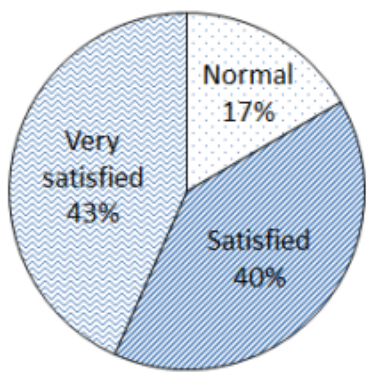

Fig. 2. Satisfaction of the required time per a session in the horticultural activity program $(\mathrm{N}=30)$. 


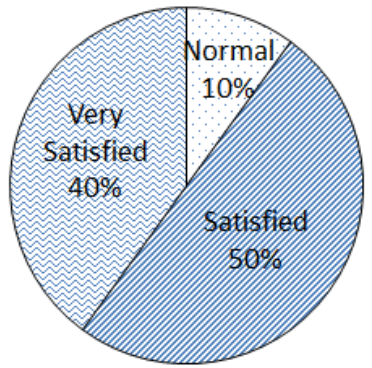

Fig. 3. Satisfaction of the frequency per a week in the horticultural activity program $(\mathrm{N}=30)$.

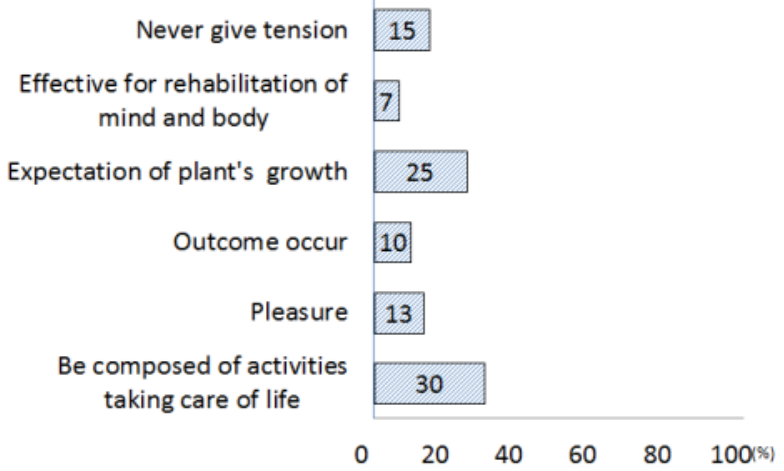

Fig. 4. Self-reported benefits of the horticultural activity program $(\mathrm{N}=30)$.

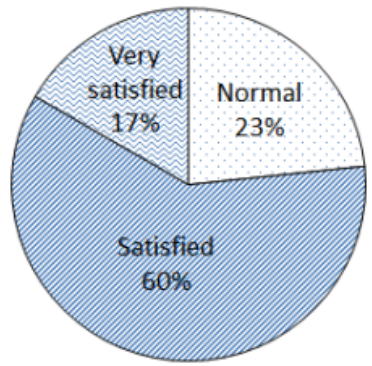

Fig. 5. Self-reported positive changes after participating in the horticultural activity program $(\mathrm{N}=30)$.

body" (Fig. 4).

To the question about the satisfaction of the self-reported positive changes after participating the horticultural activity programs, $17 \%$ said "very satisfied", $60 \%$ "satisfied", and $23 \%$, "normal" (Fig. 5). These results showed that the satisfaction of the self-reported changes was very high.

\section{Conclusion}

From the results above, it was found that positive effects on the improvement of the relationship between mother and child can be achieved through the horticultural activity program that was developed with a focus on planting activities based on factors associated with the relationship including parenting stress, self-esteem, parenting efficacy and emotional empathy.

Unlike existing programs only focusing on parenting skills, this program was developed with a focus on changes in the inner mind of mothers based on relevant factors that have an effect on the formation of a positive relationship with children.

It is expected that activities that may involve the participation of both mothers and children in horticultural activities improve the positive effects further, and it is necessary to develop various programs for mothers in various types of families such as single mothers, mothers of a disabled child, mother of adolescents, unmarried mother, etc.

\section{References}

Abidin, R.R. 1990. Parenting stress index form. Pediatric Psychology Press, Carlottersville, VA, USA.

Bae, Y.C. 2003. The effects of application of the ecological holistic learning program on the children's attitude toward the life respect. MS thesis, Inchon Univ., Inchon, Korea.

Cha, J.Y. 2009. A study on the development and verification of the effect of group counseling program applying horticulture therapy to improve the parent-child relationship of the single parent family. MS thesis, Kyungsung Univ., Busan, Korea.

Cho, K.R., G.A. Ham, and S.M. Cheon. 2013. A meta-analysis on the effects of parent education programs. J. Rehabilitation Psychology 20:369-395.

Choi, S.H. 2010. Effectiveness of reality therapy group counseling program on improving self-esteem and self-efficacy of middle school students. PhD Diss., Catholic Univ. of Daegu, Daegu, Korea.

Choi, Y.A. and J.G. Seo. 2007. Developing horticultural therapy program and its effect for reducing parenting stress. J. Korean Soc. People Plants Environ. 10:90-95.

Coopersmith, S. 1967. The antecedents of self-esteem. W.H. Freeman, San Francisco, USA.

Dorsey, S., K. Klein, and R. Forehand. 1999. Parenting self-efficacy of HIV-infected mothers: the role of social support. J. Marriage Family 61:295-305.

Gibaud-Wallston, J. and L.P. Wandersman. 1978. Development and utility of the parenting sense of competence scale. Paper presented at the annual meeting of the American Psychological Assn., Toronto, Canada.

Ha, S.Y. 2005. Effect of flower arrangement program on self-respect and self-despair for middle-aged women. Chonnam Natl. Univ., Gwangju, Korea.

Han, E.S. 2011. The effects of horticultural therapy program using 
planting on stress and parental efficacy in mothers with disabled children. MS thesis, Catholic Univ. of Daegu, Daegu, Korea.

Heo, Y.M. 2012. The effects of horticultural therapy on empathy and satisfaction of interpersonal relations of elementary school students. MS thesis, Jeju Univ., Jeju, Korea.

Hong, M.O. 2009. Effect of horticultural therapy based upon empowerment model on the improvement of self esteem and parent efficacy of disable children's mother. MS thesis, Konkuk Univ., Seoul, Korea.

Hwang, H.J., Y.A. Lee, J.E. Song, and K.C. Son. 2007. Effect of horticultural therapy based upon reality therapy on the reduction of depression, the change in parental sense of competence, and stress coping types of elementary student's mother. Kor. J. Hort. Sci. Technol. 25:268-276.

Jeong, N.J. and Y.H. Lee. 2010. The development and effects of filial therapy program with art therapy techniques applied - the case of those with maladaptive behavior child and mother. Korean J. Art Therapy 17:379-413.

Kang, J.G. 1986. Influence of self-concept, mature career consciousness and study achievement on occupational aspiration level. MS thesis, Seoul Natl. Univ., Seoul, Korea.

Kang, Y.S. 2010. The effects of a parent education program on parents' self-esteem, parental efficacy, and parent-child communication. MS thesis, Hankuk Univ. of Foreign Studies, Seoul, Korea.

Kim, H.E. 2012a. Analysis of the structural relationship among parent attachment, dysfunctional attitude, ego-identity, ego-resilience, social support, and depression of early adolescence. PhD Diss., Dong-A Univ., Busan, Korea.

Kim, M.A. 2011. The effect of mother's emotional empathy on emotional intelligence of young children. MS thesis, Myongji Univ., Seoul, Korea.

Kim, M.K. 2012b. Effect of satir model based growth and parent education program on the self-esteem and congruency of parents and adolescent children's self-esteem. PhD Diss., Dong-A Univ., Busan, Korea.

Kim, R.B. 2007. Effect of holistic horticultural therapy on the stress and attention concentration of juvenile delinquents. MS thesis, Catholic Univ. of Daegu, Daegu, Korea.

Kong, K.S. 2010. The effect of parents education based on transactionalanalysis on maternal parenting attitudes and communications. MS thesis, Sahmyook Univ., Seoul, Korea.

Lee, E.H. and S.O. Jeong. 2006. Ego identity as a mediator between parenting behaviors, peer relationships, and depression in adolescence: a structural equations analysis. Studies Korean Youth 17:213-239.

Lee, H.S. 2012. The effects of group art therapy program using 'Eum' parent education on parents' emotional empathetic capacity and parent-child communication. MS thesis, Kyungsung Univ., Busan, Korea.

Lee, S.H. 2010a. Horticultural therapy based on floral design program on self-esteem and depression of the middle-aged housewives. MS thesis, Konkuk Univ., Seoul, Korea.

Lee, Y.A. 2010b. A study on the effects of the systematic training for effective parenting of young children's parents. MS thesis,
Sahmyook Univ., Seoul, Korea.

Matsuo, E. 2005. Recommendation of the horticulture, environment, education, welfare, gardening of district. Nongmin, Tokyo.

Miller, A.L. and S.L. Olsen 2000. Emotional expressiveness during peer conflicts a predictor of social maladjustment among highrisk preschoolers. J. Abnormal child Psychology 28:339-352.

Oh, J.S. 2011. The effect of the active parenting now program on the self-esteem, child-rearing attitude and communication of the mothers of the multicultural families. MS thesis, Mokpo National Univ., Mokpo, Korea.

Park, H.J. 2004. Case-analytic study of art therapy which is for a maladjusted child. PhD Diss., Dong-A Univ., Busan, Korea.

Park, H.S. 2003. A study on mother's playfulness with her child in early childhood, parenting efficacy, and parenting stress. MS thesis, Sookmyung Women's Univ., Seoul, Korea.

Park, J.H. and O.B. Chung. 2002. The family system types of circumplex model and ego identity development in adolescence. Family and Environ. Res. 40(10):49-63.

Park, J.Y. 2014. A study on parental emotional empathy, parenting efficacy and preschooler emotional regulation: comparison of parents. MS thesis, Busan Natl. Univ., Busan, Korea.

Park, S.A., M.K. Cho, M.H. Yoo, S.Y. Kim, E.A. Im, J.E. Song, J.C. Lee, and I.G. Jun. 2016. Horticultural activity program for improving emotional intelligence, prosocial behavior, and scientific investigation abilities and attitudes in kindergarteners. HortTechnology 26(6):754-761.

Ryu, J.H. 1996. Applicability-study of training program which is about active parenting for child. PhD Diss., Seoul Women's Univ., Seoul, Korea.

Seo, H.Y. 1992. Study of adaptation of handicapped child mother and social support. MS thesis, Yonsei Univ., Seoul, Korea.

Shin, K.I. 1994. The development and application of an empathy training program for counselor education. PhD Diss., Busan Univ., Busan, Korea.

Shin, S.J. 1997. Influence of mother's parenting stress, social support and parent efficacy on parenting behavior. PhD Diss., Yonsei Univ., Seoul, Korea.

Son, K.C., S.S. Lee, and J.S. Lee. 1999. Effects of visual appreciation of oriental- or western-style flower arrangement on the changes of human brain electoencephalography. J. Kor. Soc. Hort. Sci. 40:511-514.

Son, K.C., S.Y. Kim, S.S. Lee, J.E. Song, and M.K. Cho. 2006. Programs and assessment tools for the professional horticultural therapy. KooBook, Seoul, Korea.

Suh, E.J. 2009. The effect of attachment improvement parent-education group counseling on mother's adult attachment, self-esteem, parent-child interaction and parenting efficacy. PhD Diss., Yeungnam Univ., Gyeongsan, Korea.

Yang, Y.H. 1987. A case study on the effects of STEP (Systematic training for effective parenting) program. MS thesis, Ehwa Womans Univ., Seoul, Korea.

Yeon, M.H. 1994. An evaluation on the applicability of parent effectiveness training (PET) to Korean parents. Family Environment Research. 33:107-120. 